\section{Split notochord syndrome: a case in point}

\section{Dear Editor,}

A 36-year-old female presented with low back pain and was admitted. During the anamnesis, she reported having undergone surgery, in the first days of life, for the repair of lumbosacral myelomeningocele and imperforate anus. She had been a full-term infant, born to an adolescent mother who had received no prenatal care. There were no reports of infection, drug use, or exposure to teratogenic agents during gestation. Computed tomography of the urinary tract showed ectopic kidneys, with a rotational anomaly and bilateral nephrolithiasis. In addition, as an incidental finding, we identified a congenital (morphological and structural) alteration of the lumbosacral spine, characterized by a fusion defect and failure of vertebral body segmentation, with the formation of two axes, starting from the third lumbar vertebra. Other imaging tests for the evaluation of the lumbosacral spine confirmed the findings and demonstrated two medullas within a single dural sac, separated by a thin fibrous septum (Figure 1). These findings, taken together with the clinical history, suggested split notochord syndrome (SNS) as the most likely diagnosis.

SNS results from a rare congenital malformation defined as a cleft in the spine, forming a double spinal column, due to failed fusion of the lateral ossification centers of the vertebral bodies. It occurs most often in the thoracolumbar region; when it affects the lumbosacral region, it can be accompanied by imperforate anus and meningocele. Other anomalies, involving the gastrointestinal tract, central nervous system, and genitourinary tract-manifesting as dorsal enteric fistulas, hydrocephalus, and bladder exstrophy-have been reported ${ }^{(1-3)}$. Given the scarcity of published cases, it is not possible to accurately establish associations with other abnormalities. An extensive review of the literature showed that approximately 500 cases have been reported and that only a minority of the affected individuals reach adulthood ${ }^{(4-6)}$.

In most cases of SNS, there are no reports of known exposure to teratogenic agents or a family history of birth defects.

Figure 1. Congenital morphological and structural alteration of lumbosacral spine, characterized by a fusion defect and failure of vertebral body segmentation, with the formation of two axes, starting from the third lumbar vertebra, as seen on conventional radiography $(\mathbf{A})$, computed tomography $(\mathbf{B})$, and computed tomography with 3D reconstruction (C). Axial T2-weighted magnetic resonance imaging scan showing two medullas within a single dural sac (D).
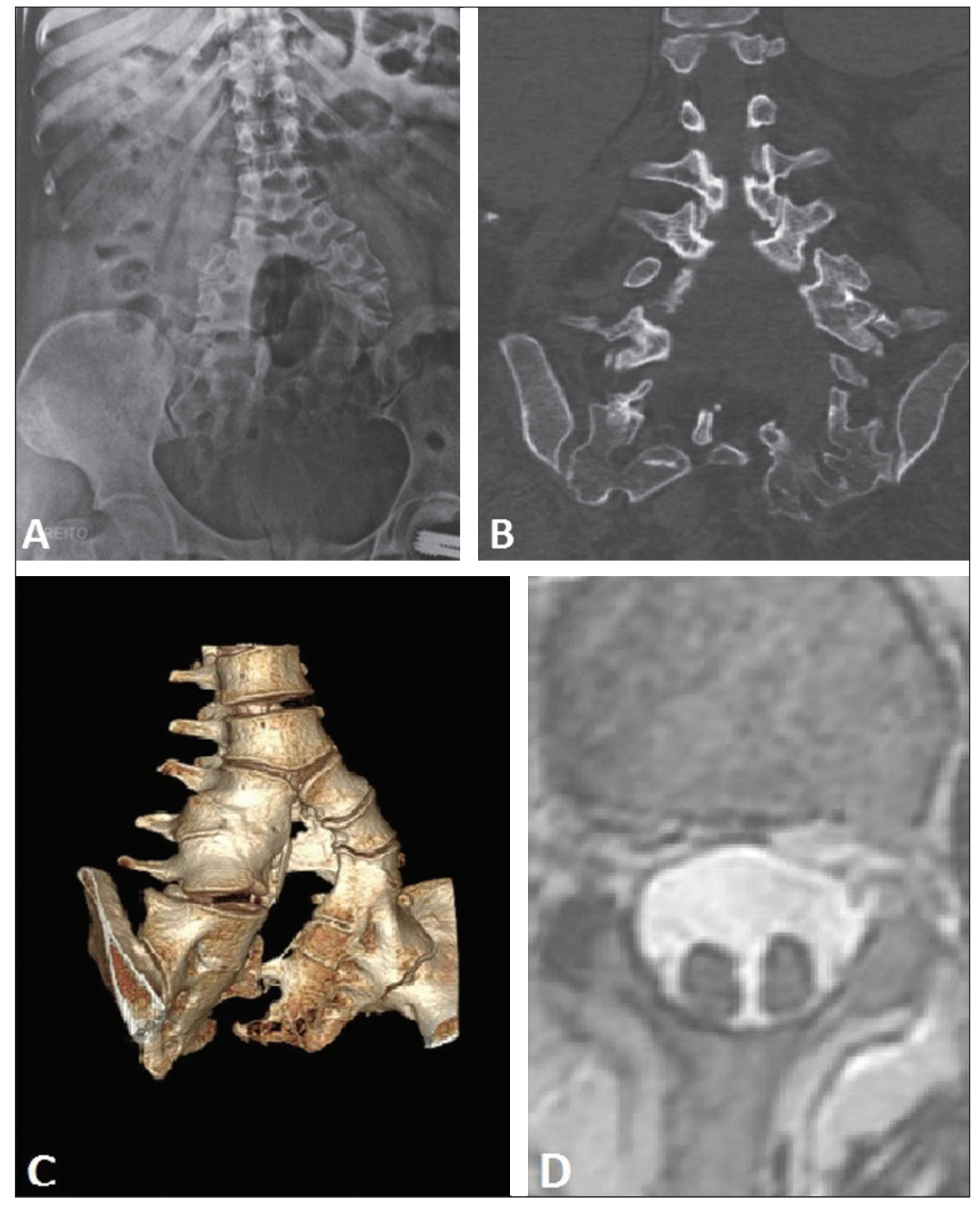
Although the embryogenesis of the anomaly remains under discussion, there is evidence that a primary defect in the initial division of the notochord, neurenteric canal, and paraxial mesoderm-with a persistent connection between the endoderm and ectoderm, causing division or deviation of the notochord-is associated with variety of malformations. Recent hypotheses are based on vascular impairment of the inferior neural structure, which would prevent the closure of the neural tube ${ }^{(2,6,7)}$.

Double spines and spinal cords can be observed in SNS and in caudal duplication syndrome, covering a wide spectrum of malformations, ranging from simple fibrous bands dividing the medulla to complete duplication of the caudal structures. A diagnosis of caudal duplication syndrome should be considered only when there is also duplication of vascular structures or organs, the genitourinary tract, the gastrointestinal tract, and the distal neural tube ${ }^{(8)}$.

Among individuals with SNS, the reported survival and prognosis are poor. Including the case reported here, there have been only five reports in which the patient survived. However, with the advances in surgical techniques and neonatal intensive care, there is a trend toward better outcomes ${ }^{(2)}$. The aim of this case report was to discuss the diagnosis of SNS, a rare condition, associated with congenital anomalies and high mortality. Therefore, we propose that, when spinal defects are detected, a detailed investigation of the associated findings be carried out, thus avoiding diagnostic errors and delays.

\section{REFERENCES}

1. Srivastava P, Gangopadhyay AN, Gupta DK, et al. Split notochord syndrome associated with dorsal neuroenteric fistula: a rare entity. J Pediatr Neurosci. 2010;5:135-7.

2. Jesus LE, França CG. Síndrome do notocórdio fendido, variante rara do cisto neuroentérico. J Pediatr (Rio J). 2004;80:77-80.

3. Asghar A, Ashraf J, Tareen F, et al. An experience with four cases of split notochord syndrome and review of literature. Pakistan Journal of Medical Sciences. 2002;18:257-61.

4. Mahapatra AK. Split cord malformation - a study of 300 cases at AIIMS 1990-2006. J Pediatr Neurosci. 2011;6(Suppl 1):S41-5.

5. Ersahin Y. Split cord malformation types I and II: a personal series of 131 patients. Childs Nerv Syst. 2013;29:1515-26.

6. Mirza B, Sheikh A. Split notochord syndrome with neuroenteric fistula, a rare malformation. WebmedCentral Paediatric Surgery. 2010; 1(9):WMC00571.

7. Hoffman CH, Dietrich RB, Pais MJ, et al. The split notochord syndrome with dorsal enteric fistula. AJNR Am J Neuroradiol. 1993;14:622-7.

8. Sur A, Sardar SK, Paria A. Caudal duplication syndrome. J Clin Neonatol. 2013;2:101-2.

Camila Soares Moreira de Sousa ${ }^{1}$, Bárbara Bezerra de Castro ${ }^{1}$, Carla Lorena Vasques Mendes de Miranda ${ }^{1}$, Breno Braga Bastos ${ }^{2}$, Marcelo Coelho Avelino ${ }^{3}$

1. Med Imagem - Radiologia, Teresina PI, Brazil. 2. UDI 24 horas, Teresina, PI, Brazil. 3. Hospital de Urgência de Teresina Prof. Zenon Rocha, Teresina, PI, Brazil. Mailing address: Dra. Camila Soares Moreira de Sousa. Med Imagem - Radiologia. Rua Paissandu, 1862, Centro. Teresina, PI, Brazil, 64001-120. E-mail: camilasoares_@hotmail.com.

http://dx.doi.org/10.1590/0100-3984.2015.0251

\section{Acupuncture needle fragments identified on X-ray and computed tomography studies of chest}

\section{Dear Editor,}

A 75-year-old male patient underwent chest X-ray and computed tomography of the thorax (Figure 1) for postoperative evaluation of myocardial revascularization. Small metallic objects were identified in the subcutaneous tissue of the back. The objects were similar in size but varied in form; some were linear and others had some degree of curvature. Those findings are consistent with acupuncture needle fragments.

Traditional Chinese acupuncture has been practiced for millennia. Approximately 40 years ago, it was introduced into medical practice in Brazil, where it is now widely used for the prevention and treatment of chronic pain. It consists in the insertion of needles into the subcutaneous tissue; the needles are left in place for up to $15 \mathrm{~min}$, after which they are removed ${ }^{(1)}$. In some acupuncture modalities, the needles are inserted into the subcutaneous tissue and the protruding part of each is cut off; the remaining fragments are thus permanently maintained in the tissue, providing continuous neurological stimulation ${ }^{(2)}$ The needles have a maximum diameter of approximately $1 \mathrm{~mm}$ and a maximum length of $1.5 \mathrm{~cm}^{(3)}$. The needles are preferably

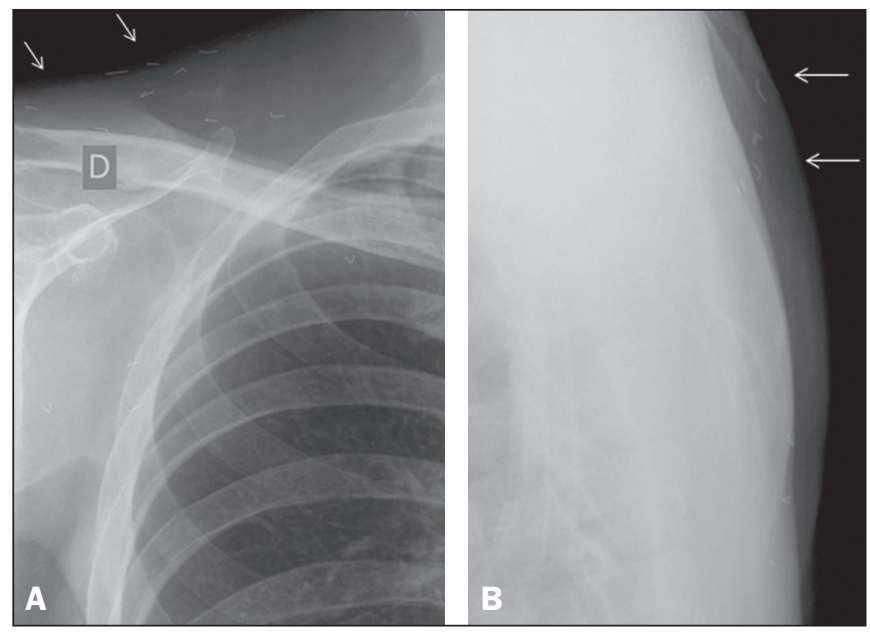

Figure 1. Chest $X$-rays, in frontal and profile views (A and $\mathbf{B}$, respectively), showing small metallic objects in the subcutaneous tissue of the back and supraclavicular region, with similar sizes and varied forms, some being linear and others having some degree of curvature. C,D: Axial positron emission tomography/ computed tomography of the thorax, showing small objects, the density of which is consistent with metal, in the subcutaneous tissue, predominantly in the back.

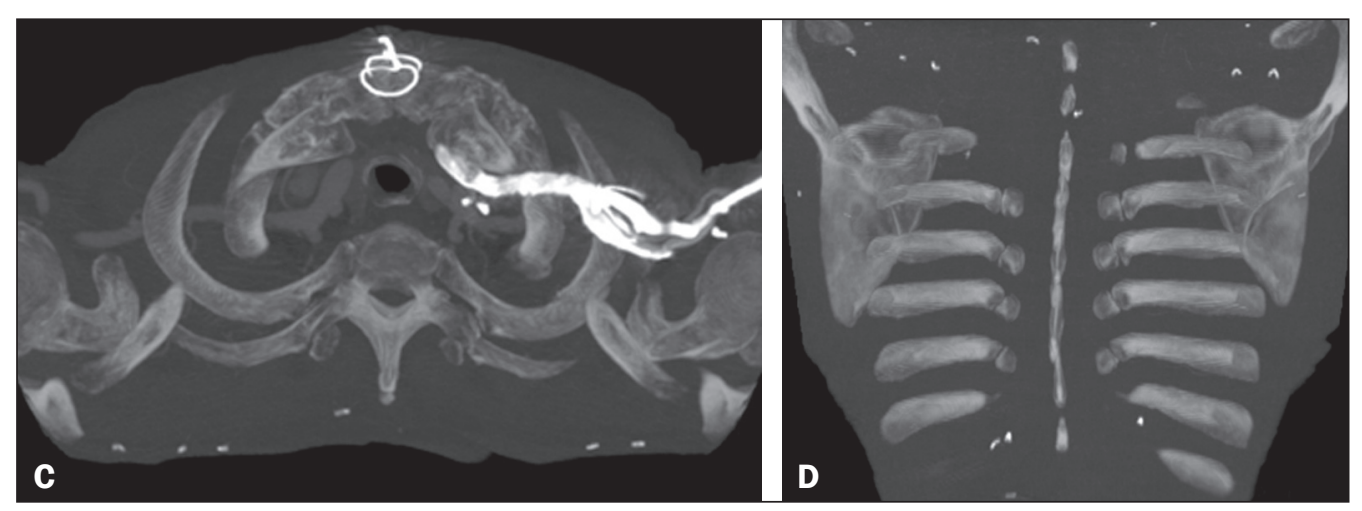

